\title{
Change in the tropical cyclone activity around Korea by the East Asian summer monsoon
}

\author{
Jae-Won Choi, , Yumi Cha and Jeoung-Yun Kim
}

\begin{abstract}
Correlation between the frequency of summer tropical cyclones (TCS) affecting Korea and the East Asian summer monsoon index (EASMI) was analyzed over the last 37 years. A clear positive correlation existed between the two variables, and this high positive correlation remained unchanged even when excluding El Niño-Southern Oscillation (ENSO) years. To investigate the causes of the positive correlation between the two variables in non-ENSO years, after the 8 years with the highest EASMI (high EASMI years) and the 8 years with the lowest EASMI (low EASMI years) were selected, and the average difference between the two phases was analyzed. In high EASMI years, in the difference between the two phases regarding 850 and $500 \mathrm{hPa}$ streamline, anomalous cyclones were reinforced in the tropical and subtropical western North Pacific, while anomalous anticyclones were reinforced in mid-latitude East Asian areas. Due to these two anomalous pressure systems, anomalous southeasterlies developed near Korea, with these anomalous southeasterlies playing the role of anomalous steering flows making the TCs head toward areas near Korea. In addition, a monsoon trough strengthened more eastward, and TCs in high EASMI years occurred more in east ward over the western North Pacific.
\end{abstract}

Keywords: Tropical cyclones, East Asian summer monsoon, Korea

\section{Background}

While many studies performed on changes in TCs in individual tropical cyclone (TC) genesis basin or major regions affected by TC activity, studies conducted on TCs that affected or made landfall on Korea are rare. Choi and Kim (2007) showed that the frequency of TCs that made landfall on Korea had been increasing since the middle of the 1990s and increases in the landfalling frequency of strong TCs had been more prominent. As for these results, they analyzed that the reason was that as the western North Pacific subtropical high (WNPSH) shrunk toward the east, the paths of TCs moved to the east so that the frequency of passing through China before making landfall on Korea decreased. Choi et al. (2010) applied the statistical change-point analysis used in a study by Ho et al. (2004) to changes in the frequency of TCs that made

*Correspondence: choikiseon@daum.net National Institute of Meteorological Sciences, 33, Seohobuk-ro, Jeju 63568, South Korea landfall on Korea. Based on the results, they showed that the analysis period for the past 54 years (1951-2004) could be divided into three periods and that the landfalling frequency of strong TCs was the highest in the most recent period. Park et al. (2006) showed that this increasing tendency was clear in TCs that affected Korea. In particular, Choi and Kim (2011) showed that the frequency of TCs that affected Korea increased since the early 1980s after applying the statistical change-point analysis.

However, the frequency of TCs that affected Korea decreased abnormally since the late 2000 s so that TC season forecasters have been experiencing considerable difficulties when they were forecasting TCs. Furthermore, since the above studies used dataset obtained only until the early 2000, opinions indicating that the activities of TCs that affected or made landfall on Korea should be investigated again using dataset with more long period have been raised (Choi and Kim 2011; Choi et al. 2009).

The East Asia region has been suffering from enormous property and human life damage every year due to TCs. 
In Korea, after the landing of typhoon 'RUSA' in 2002, the highest record (the $24 \mathrm{~h}$ accumulated precipitation of $870.5 \mathrm{~mm}$ ) since the time when weather observation began in Korea was observed in Gangneung (Park and Lee 2007). In addition to Korea, the highest records of strong winds, heavy rains, and waves that accompanied by TCs have been renewed in Japan, Taiwan, and Philippines (Kim et al. 2005; Lyon and Camargo 2009; Pan et al. 2010).

Efforts have been actively made to find the cause of these abnormal TC activities occurring in various East Asia regions using climate factors. Among those, climate factor that has received the most keen attention thus far in relation to efforts to understand the characteristics of TC activity is El Niño-Southern Oscillation (ENSO) (Wang and Chan 2002; Chu 2004; Wu et al. 2004). In general, TCs in El Niño phase mainly occur in the southeast quadrant of western North Pacific and tend to make landfall on or affect the east coast of China, Korea, or Japan. On the other hand, TCs in La Niña phase occur in the northwest quadrant of western North Pacific and tend to move westward or northwestward. Therefore, TCs mainly make landfall on Philippines, southern China, or Indochina Peninsula. Therefore, TCs in El Niño phase show a little longer life-span and a little higher intensity than those in La Niño phase. Meanwhile, Ho et al. (2005) tried to associate the cause of changes in TC activity in the western North Pacific with atmospheric circulations in the Southern Hemisphere. They showed that during the positive Antarctic Oscillation (AAO) phase, TC passage frequency increased due to WNPSH reinforced in the East Asian middle latitude region but decreased in regions in the vicinity of the South China Sea. Wang and Fan (2007) found that AAO and TC genesis frequency in the western North Pacific had negative correlations during June to September (JJAS). In that study, they showed that during the positive AAO phase, vertical wind shear increased, the vertical structure of lower anticyclone/ upper cyclone developed in the western North Pacific, and sea surface temperatures dropped so that unfavorable environments for the occurrence of TCs were formed. Meanwhile, Wang et al. (2007) investigated the relationship between the North Pacific Oscillation (NPO) and TC genesis frequency in the western North Pacific and the subtropical Atlantic during JJAS. Based on the results, they suggested that TC genesis frequency and the NPO showed positive correlations and negative correlations in the former and latter basins, respectively, and that changes in TC genesis frequency between the two basins were made through teleconnection patterns. As the recent study, Choi and Byun (2010) analyzed changes in TC activity in the western North Pacific according to Pacific-Japan teleconnection patterns (PJ pattern).
They showed that during positive PJ patterns, because anomalous cyclonic circulation and anomalous anticyclonic circulation were reinforced in low and middle latitude regions of East Asian, respectively, the anomalous southerlies reinforced in the mid-latitude regions played the role of steering flows to have TCs move to these regions more easily. However, studies on the relationship between the Arctic Oscillation (AO) which is one of the most clear zonal circulation (or annular) modes in winter in the Northern Hemisphere and TC activity in the western North Pacific cannot be easily found. Only Choi and Byun (2010) analyzed changes in TC activity in the western North Pacific according to AO phases during July to September. Studies on the relationship between TC activity and the $\mathrm{AO}$ in the Atlantic are also rare (Larson et al. 2005; Xie et al. 2005).

However, most of studies on TCs that affected or made landfall on Korea have been concentrated on the precipitation and strong winds that accompanied by TCs or their modeling due to the property and human life damage (Kim and Lee 2007; Kim et al. 2010; Park and Kim 2010). However, understanding the trend of the annual frequency of TCs that affected or made landfall on Korea and those climate factors that cause the trend should be also helpful for seasonal forecasting of TCs or preparation for disasters resulting from TCs. Therefore, the present study examines the effects of East Asian summer monsoon on changes in the frequency of TCs that affect Korea.

In the present study, materials and analysis methods are introduced in "Data and methods" section, and East Asian summer monsoons are defined in "Relationship between TC frequency around Korea and EASM" section. In "Differences between high EASMI years and low EASMI years" section, the relationships between the frequency of TCs that affect Korea and East Asian summer monsoon are analyzed, and in "Summary and conclusion" section, large-scale environments are examined to figure out the cause of these relationships. The present study is summarized in "Relationship between TC frequency around Korea and EASM" section.

\section{Data and methods}

\section{Data}

The TC datasets in this study were obtained from the TC best track provided by Regional Specialized Meteorological Center (RSMC)-Tokyo Typhoon Center. These datasets consist of TC name, latitude, and longitude location of TC, TC central pressure, and TC Maximum Sustained Wind Speed (MSWS), which were observed in every $6 \mathrm{~h}$ for 37 years (1977-2013). TC is generally classified into four classes by the criteria of MSWS as follows: Tropical Depression (TD, MSWS $<17 \mathrm{~m} \mathrm{~s}^{-1}$ ), Tropical Storm (TS, 
$17 \mathrm{~m} \mathrm{~s}^{-1} \leq$ MSWS $\leq 24 \mathrm{~m} \mathrm{~s}^{-1}$ ), Severe Tropical Storm (STS, $25 \mathrm{~m} \mathrm{~s}^{-1} \leq$ MSWS $\leq 32 \mathrm{~m} \mathrm{~s}^{-1}$ ), and Typhoon (TY, MSWS $\geq 33 \mathrm{~m} \mathrm{~s}^{-1}$ ). Along with the four classes of TC above, this study included extratropical cyclone, which was transformed from TC. This was because such extratropical cyclone also incurred great damage on property and human in the mid-latitude regions of East Asia.

Moreover, this study also used the variables of geopotential height (gpm), zonal and meridional winds $\left(\mathrm{m} \mathrm{s}^{-1}\right)$, precipitable water $\left(\mathrm{kgm}^{-2}\right)$, and relative humidity (\%) from National Centers for Environmental PredictionNational Center for Atmospheric Research (NCEPNCAR) reanalysis in 1977-2013 (Kalnay et al. 1996; Kistler et al. 2001). This NCEP-NCAR reanalysis dataset consisted of spatial resolution such as latitude and longitude $2.5^{\circ} \times 2.5^{\circ}$ and 17 vertical levels (relative humidity is 16 vertical levels and precipitable water is 1 level). Also, velocity potential consisted of a spatial resolution such as latitude and longitude $192 \times 94$ and 5 sigma levels.

The NOAA Extended Reconstructured monthly Sea Surface Temperature (SST) (Reynolds et al. 2002), available from the same organization, was also used. The datasets have a horizontal resolution of $2.0^{\circ} \times 2.0^{\circ}$ latitude-longitude and are available for the period of 1854 to the present day.

In addition, the Climate Prediction Center (CPC) Merged Analysis of Precipitation (CMAP) dataset (Xie and Arkin 1997), the horizontal spatial resolution of which is the same as the NCEP-NCAR reanalysis dataset. These datasets are based on the monthly average and are available from 1979 to the present day. The CMAP dataset, which is global precipitation data that covers the ocean, are derived by merging rain gauge observations, five different satellite estimates, and numerical model outputs.

\section{Methods}

In order to calculate TC passage frequencies, each TC was calculated after being relocated within a $5^{\circ} \times 5^{\circ}$ grid. Even if a TC passed over the same grid multiple times, it was regarded as a single passage. TC genesis frequencies were also calculated in the above manner.

TC intensity is defined as the TC central pressure and TC MSWS observed in the vicinity of Korea using the TC best track data at intervals of $6 \mathrm{~h}$ provided by the RSMCTokyo typhoon center.

This study used the Student's $t$ test to determine significance (Wilks 1995). In case, that two independent time series follow a $t$ distribution and their time averages are denoted as $\overline{x_{1}}$ and $\overline{x_{2}}$, respectively, the test statistic is given by

$$
t=\frac{\overline{x_{1}}-\overline{x_{2}}}{\left(s_{1}^{2} / n_{1}+s_{2}^{2} / n_{2}\right)^{1 / 2}},
$$

where $s_{1}$ and $s_{2}$ are standard deviations, and $n_{1}$ and $n_{2}$ are numbers of the two time series, respectively. From the above formula, if the absolute value of $t$ is greater than threshold values with a level of significance, the null hypothesis would be rejected at the $\alpha(\times 100) \%$ significance level.

The vertical wind shear (VWS) to diagnose the largescale condition is calculated as follows:

$$
\text { VWS }=\sqrt{\left(u_{200-850}\right)^{2}+\left(v_{200-850}\right)^{2}} .
$$

Here, $u$ and $v$ indicate the zonal and meridional flows, respectively. 200 and 850 represent 200 and $850 \mathrm{hPa}$ levels, respectively (Wingo and Cecil 2010).

In this study, summer is defined as the period from June to August. This is because EASM rainfall is concentrated on these 3 months (Wang and Fan 1999).

Korean region affected by $\mathrm{TCs}\left(30^{\circ}-45^{\circ} \mathrm{N}, 120^{\circ}-130^{\circ} \mathrm{E}\right)$, as shown in Fig. 1.

\section{Definition of EASM index (EASMI)}

In the present study, the EASMI was defined using the Dynamical Normalized Seasonality (DNS) index developed by Li and Zeng (2002, 2003, 2005). The basic concept of the DNS index is based on the intensity of the normalized seasonality of wind fields. Since monsoons have very strong seasonal variations of wind directions, defining strong and weak monsoons using the magnitude of the seasonality of wind fields is valid. Using this basic concept of monsoons, the DNS index through the following equation.

$$
\delta_{m n}=\frac{\left\|\bar{V}_{1}-V_{m n}\right\|}{\|\bar{V}\|}-2,
$$

where $\bar{V}_{1}$ and $\bar{V}$ are mean January climatological wind vectors and January and June-August climatological wind vectors, respectively, and $V_{m n}$ means the monthly wind vector for month $m$ in year $n$. For example, if summer of certain year is summer (June-August) of 2004, $m$ and $n$ denote average of June-August and 2004, respectively. Hereafter, the EASMI is defined as the area-averaged seasonally (June-August) DNS at $850 \mathrm{hPa}$ in the East Asian monsoon domain $\left(10^{\circ}-40^{\circ} \mathrm{N}, 110^{\circ}-140^{\circ} \mathrm{E}\right)$. ' 2 ' indicates the constant to emphasize the standard deviation of DNS index. Therefore, EASMI in the current study corresponds with the classical definition of monsoon that is the seasonal difference of wind direction (Ramage 1971). However, these study results showed that there were clear negative correlations between the EASMI calculated through the above equation and the June-August rainfall in the middle and lower reaches of the Yangtze River in China to prove that the above definition of EASMs was valid. That is, the definition means 


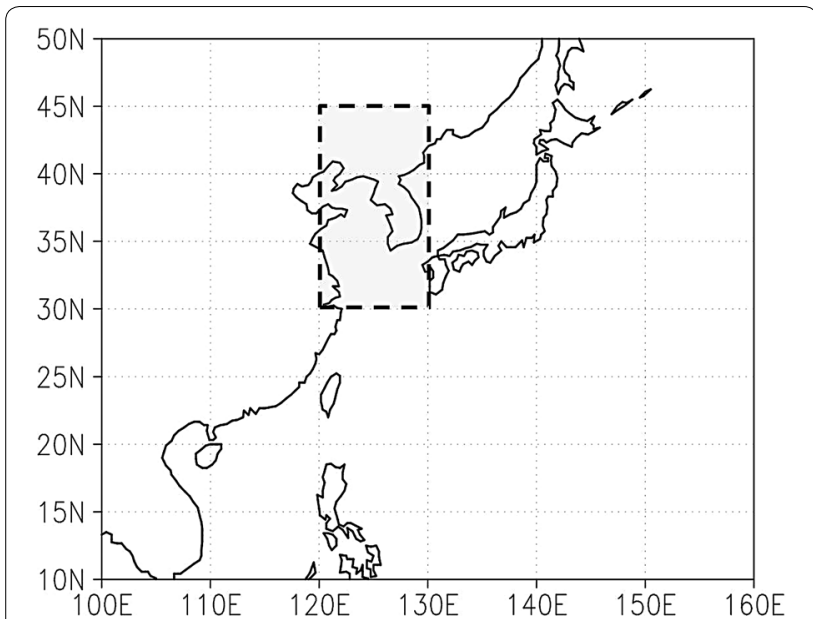

Fig. 1 Definition of area of Korea that affected by TC in summer (June-August)

that when the EASMI is higher (lower), EASMs are weaker (stronger).

\section{Relationship between TC frequency around Korea and EASM}

Figure 2 shows the time series of the frequency of TCs that affected Korea in summer and the EASMI over the last 37 years (1977-2013). Both time series show clear interannual and interdecadal variations. In particular, inphase relationships between the two time series are clear so that the two variables show a high positive correlation coefficient of 0.75 at the $99 \%$ confidence level. This means that if summer monsoons are strengthened (weakened) in the East Asian region, the frequency of TCs that affect Korea tend to decrease (increase).
However, if trends are removed from the two time series, the correlations may differ. Therefore, the trend of the frequency of TCs that affected Korea was analyzed. According to the results, the trend in the time series of the frequency of TCs that affected Korea showed a slightly decreasing tendency (thick solid line). However, this change in the trend is not statistically significant. Therefore, even when trends were removed from the two time series, the correlation coefficient between the two variables changed hardly. Meanwhile, the correlation between the two variables may increase due to the effect of ENSO. Therefore, the time series of the two variables were analyzed after removing summer El Niño years (1982, 1987, 1991, 1997, 2002, 2004, and 2009) and La Niña years $(1985,1988,1998-$ 2000, and 2010) (Fig. 3). It can be seen that even when ENSO years had been removed, the in-phase relationship between the two variables was clearly maintained. Therefore, the correlation between the two variables showed a positive correlation coefficient of 0.73 at the 99\% confidence level. This result means that ENSO does not have great effects on the relationship between the two variables.

In addition, this study conducted a partial correlation analysis to see the effect of ENSO on TC frequency in the vicinity of Korea (Table 1). The correlation coefficient between the Niño-3.4 index and the EASMI is 0.31, which is significant at the $90 \%$ confidence level. The correlation coefficient between the Niño-3.4 index and TC frequency near Korea is 0.17 , which is not statistically significant. After the Niño-3.4 index is controlled, the correlation coefficient between TC frequency near Korea and EASMI is 0.72 , which is significant at the $99 \%$ confidence level.

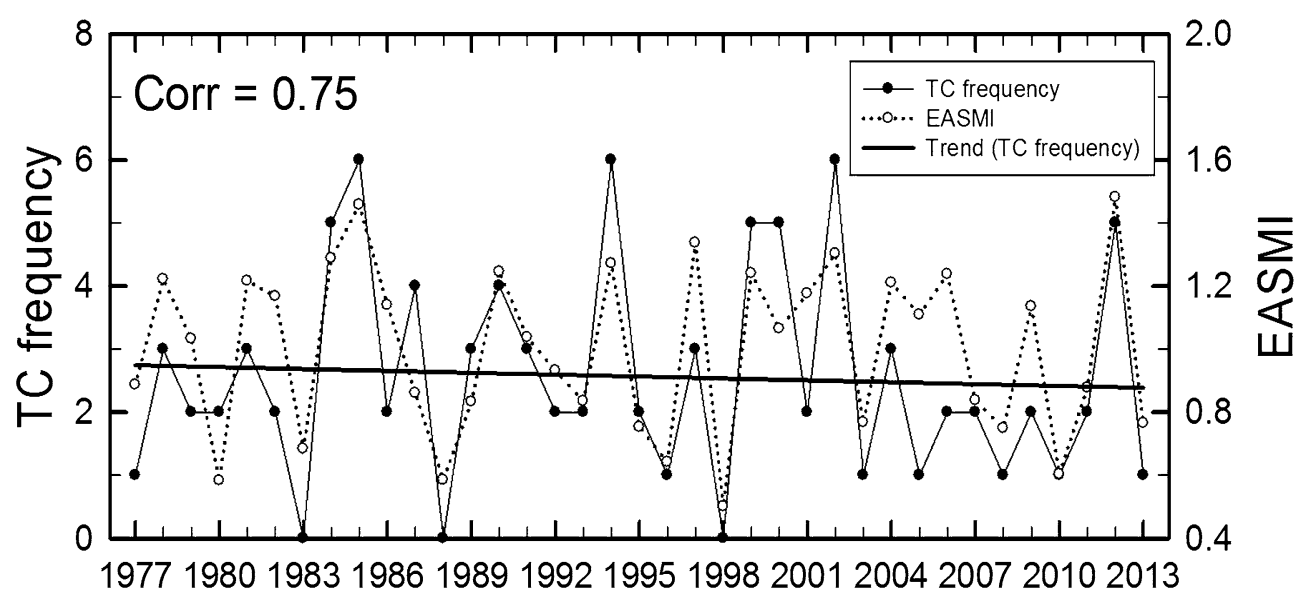

Fig. 2 Time series of the frequency of TC that affects Korea (solid line with a closed circle) and East Asian Summer monsoon index (EASMI) (dotted line with an open circle) and the trend of TC frequency 


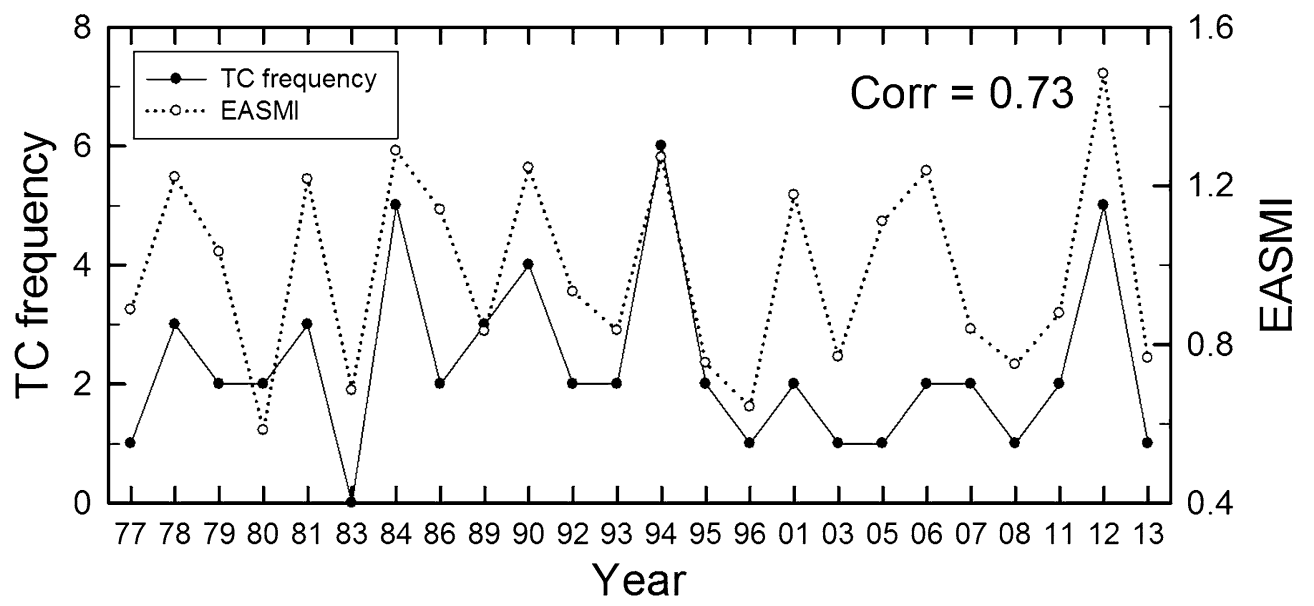

Fig. 3 Time series of the frequency of TC that affects Korea (solid line with a closed circle) and East Asian summer monsoon index (EASMI) (dotted line with an open circle) except for El Niño-Southern Oscillation (ENSO) years

Table 1 Results of partial correlation analysis

\begin{tabular}{llll}
\hline Controlled variable & WNPMI & TC frequency & Niño-3.4 index \\
\hline None & & & 0.31 \\
WNPMl & 1 & 0.75 & 0.17 \\
TC frequency & & 1 & 1 \\
Niño-3.4 index & & & \\
Nino-3.4 index & & & \\
WNPMl & 1 & 0.72 & \\
TC frequency & 0.72 & 1 & \\
\hline
\end{tabular}

\section{Differences between high EASMI years and low EASMI years}

To examine the cause of the positive correlation existing between the two variables as stated in the above analysis results, 8 years having the highest EASMI (hereinafter referred to as high EASMI years) and 8 years having the lowest EASMI (hereinafter referred to as low EASMI years) were selected after excluding ENSO years (Table 2). While none of the high EASMI years had fewer than 3TCs except for 2001 and 2006, all the low EASMI years showed fewer than 3TCs except for 1989. Therefore, 3.8TCs on average affected Korea during the high EASMI years, while 1.4TCs on average affected Korea during the low EASMI years with a difference of approximately 2.4TCs between the two groups. This difference is significant at the 95\% confidence level. Therefore, in Sections hereinafter, the difference between the average in the high EASMI years and the average in the low EASMI years is analyzed.

\section{TC activity}

First, differences in TC genesis frequency between the two groups were analyzed (Fig. 4a). Overall, TCs in high
Table 2 TC frequency around Korea on high EASMI years and low EASMI years

\begin{tabular}{lllll}
\hline \multicolumn{2}{l}{ High EASMI years } & & \multicolumn{2}{l}{ Low EASMI years } \\
\cline { 1 - 2 } \cline { 5 - 5 } Year & TC frequency & & Year & TC frequency \\
\hline 1978 & 3 & & 1980 & 2 \\
1981 & 3 & 1983 & 0 \\
1984 & 5 & 1989 & 3 \\
1990 & 4 & 1995 & 2 \\
1994 & 6 & 1996 & 1 \\
2001 & 2 & & 2003 & 1 \\
2006 & 2 & 2008 & 1 \\
2012 & 5 & & 2013 & 1 \\
Average & 3.8 & Average & 1.4 \\
\hline
\end{tabular}

EASMI years showed a tendency of occurring in the east waters of the western North Pacific, while those in low EASMI years showed a tendency of occurring in the west waters of the western North Pacific. These tendencies can be seen by analyzing the average TC genesis location of each group. While the average TC genesis location in high EASMI years was $15.5^{\circ} \mathrm{N}$ and $142.4^{\circ} \mathrm{E}$, the average TC genesis location in low EASMI years was $15.4^{\circ} \mathrm{N}$ and $135.0^{\circ} \mathrm{E}$. Therefore, the two groups showed almost no difference in latitude but showed a difference of about $8^{\circ}$ in longitude. This difference in longitude is significant at the 99\% confidence level (The difference in latitude is not statistically significant).

Meanwhile, overall, more TC genesis cases in the western North Pacific are distributed in high EASMI years than in low EASMI years. Therefore, TC genesis frequencies in individual 8 years in each group were examined (Table 3). While none of high EASMI years had fewer 


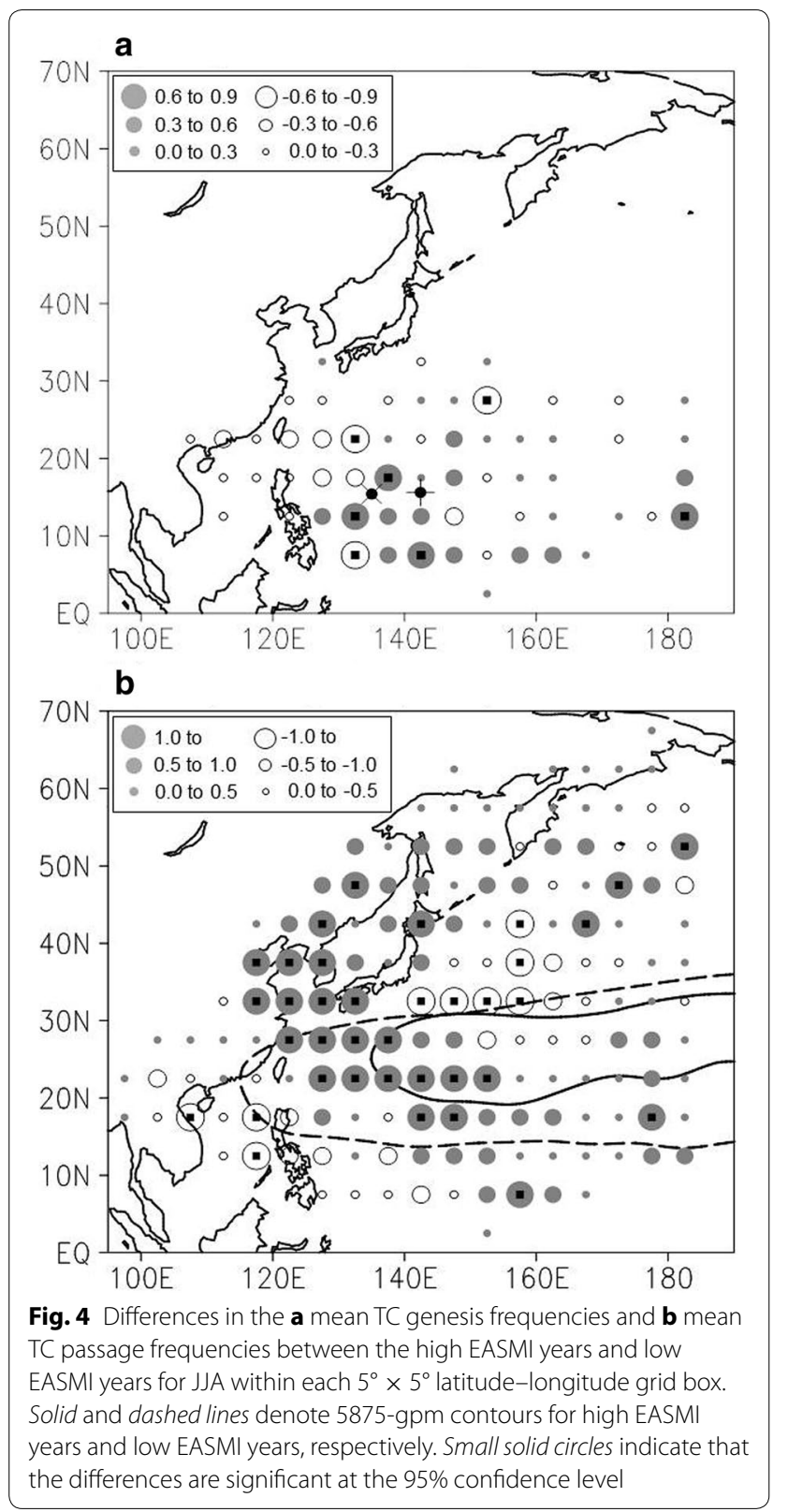

than 11TCs, all low EASMI years except for 1989, 1996, and 2013 showed fewer than 11TCs. Therefore, while the average TC genesis frequency in high EASMI years was approximately $13.6 \mathrm{TCs}$, the average TC genesis frequency in low EASMI years was approximately 10TC with a difference of approximately 3.6TCs. This difference is significant at the 95\% confidence level. Therefore, it can be seen that in high EASMI years, not only more TCs occurred than those occurred in low EASMI years but also the frequency of TCs that affected Korea was higher.

In addition, differences in TC passage frequencies between the two groups were analyzed (Fig. 4b). In high
Table 3 TC genesis frequency on high EASMI years and low EASMI years

\begin{tabular}{lllll}
\hline \multicolumn{2}{l}{ High EASMI years } & & \multicolumn{2}{l}{ Low EASMI years } \\
\cline { 1 - 2 } Year & TC frequency & & Year & TC frequency \\
\hline 1978 & 15 & & 1980 & 7 \\
1981 & 15 & 1983 & 9 \\
1984 & 12 & 1989 & 14 \\
1990 & 13 & 1995 & 9 \\
1994 & 18 & 1996 & 11 \\
2001 & 13 & 2003 & 8 \\
2006 & 11 & 2008 & 7 \\
2012 & 12 & 13.6 & 2013 & 15 \\
Average & 12 & Average & 10.0 \\
\hline
\end{tabular}

EASMI years, TCs showed a tendency to move from the far southeastern sea of the Philippines, pass the East China Sea, and move northward toward Korea and Japan. On the other hand, in low EASMI years, TCs showed a tendency to move from the southeastern sea of the Philippines, pass the South China Sea, and make landfall on the Indochina Peninsula. Earlier, it was identified that TCs in high EASMI years mainly occurred in the east waters of the western North Pacific. Wang and Chan (2002) showed that TCs that occurred in the east waters of the western North Pacific showed a tendency to move northward toward mid-latitudes of East Asia, while TCs that occurred in the west waters had a strong tendency to move westward toward the southeastern region of China and the Indochina Peninsula. The results in the present study were consistent with the results of Wang and Chan (2002). Eventually, it can be seen that dipole patterns appear between the southeastern region and the northeastern region of East Asia from the difference in TC passage frequencies between the two groups.

Meanwhile, the differences in TC genesis locations and TC tracks between the two groups identified earlier can affect differences in TC intensity between the two groups. Therefore, differences in TC intensity between the two groups were analyzed (Fig. 5). Overall, TC intensity is higher in high EASMI years than in low EASMI years. The TC central pressure in high EASMI years was lower than that in low EASMI years by approximately $4 \mathrm{hPa}$ (Fig. 5a), and TC MSWS in high EASMI years was higher than that in low EASMI years by approximately $7 \mathrm{kts}$. The difference in the two variables between the two groups is significant at the 95\% confidence level. The reason why TC intensity is higher in high EASMI years than in low EASMI years as such can be found in the TC passage frequency analyzed earlier. In high EASMI years, there was sufficient time to obtain energy from the sea to maintain TC intensity, while TCs were moving northward toward 


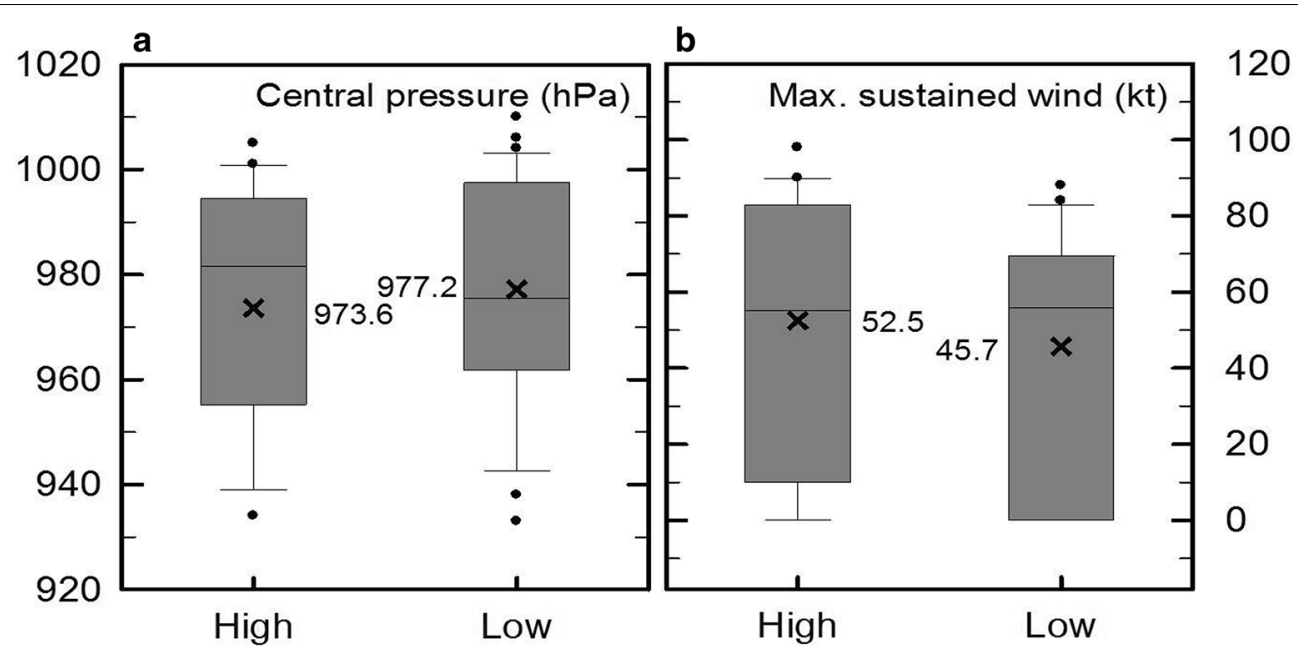

Fig. 5 TC $\mathbf{a}$ central pressure and $\mathbf{b}$ maximum sustained wind speed around Korea. The boxes show the 25th and 75th percentiles, the lines in the boxes mark the median, and the circles are values below (above) the 25th (75th) percentiles of distribution. The numbers to the right and left sides of the figure represent average values (cross marks) for the high EASMI and low EASMI years, respectively

Korea after occurring in the far southeastern sea of the Philippines. On the other hand, TC intensity could not help being weakened in low EASMI years because the time to obtain energy from the sea to maintain TC intensity was not insufficient, while TCs were moving the short distance from the southeastern sea of the Philippines to the Indochina Peninsula region, and TCs were weakened to TDs or dissipated as soon as they made landfall on the Indochina Peninsula. This is consistent with the results of Wang and Chan (2002) indicating that TC intensity was higher when TCs occurred in the southeastern sea of the western North Pacific.

\section{Large-scale environments}

To examine the cause of the positive correlation between EASM and TC frequency around Korea identified earlier, differences in large-scale environments between the two groups were analyzed.

First, to investigate differences in precipitable water between the two groups, while positive anomalies were shown in the western North Pacific, negative anomalies were shown in regions ranging from the central region of China, passing through the East China Sea to the east waters of Japan (Fig. 6a). Differences in precipitation between the two groups also show similar spatial distributions (Fig. 6b). While positive anomalies were shown in the western North Pacific south to $25^{\circ} \mathrm{N}$, negative anomalies were shown in mid-latitudes of East Asian. These results well coincide with the spatial distribution of differences in precipitation between high EASMI years and low EASMI years shown in Li and Zeng (2002, 2003, 2005). From the results of the two analyses, it can be seen that in high EASMI years, while EASM was weakened, western North Pacific summer monsoon (WNPSM) were reinforced.

Based on the difference in $500 \mathrm{hPa}$ streamlines between the two variables, it can be seen that while anomalous cyclonic circulations were reinforced in the western North Pacific, anomalous anticyclonic circulations were reinforced in mid-latitudes in the analysis area (Fig. 7a). In particular, the center of the anomalous cyclonic circulations was located on the east sea of Taiwan, and the center of the anomalous anticyclonic circulations was located on the east sea of Japan. This anomalous pressure system pattern is similar to the positive PJ teleconnection pattern (Nitta 1986, 1987, 1989). As stated above, Choi and Byun (2010) analyzed changes in TC activity in the western North Pacific according to Pacific-Japan teleconnection patterns (PJ pattern). They showed that during positive PJ patterns, because anomalous cyclonic circulation and anomalous anticyclonic circulation were reinforced in low and middle latitude regions of East Asian, respectively, the anomalous southerlies reinforced in the mid-latitude regions played the role of steering flows to have TCs move to these regions more easily. Due to these two anomalous pressure system patterns in East Asia, regions around Korea were affected by anomalous southeasterlies. In high EASMI years, these anomalous southeasterlies can play the role of anomalous steering flows to have TCs occurred in the western North Pacific move toward regions around Korea. Therefore, TC frequency around Korea becomes high in this group. The results of analysis of differences in $850 \mathrm{hPa}$ streamlines between the two groups also show similar spatial distributions to 


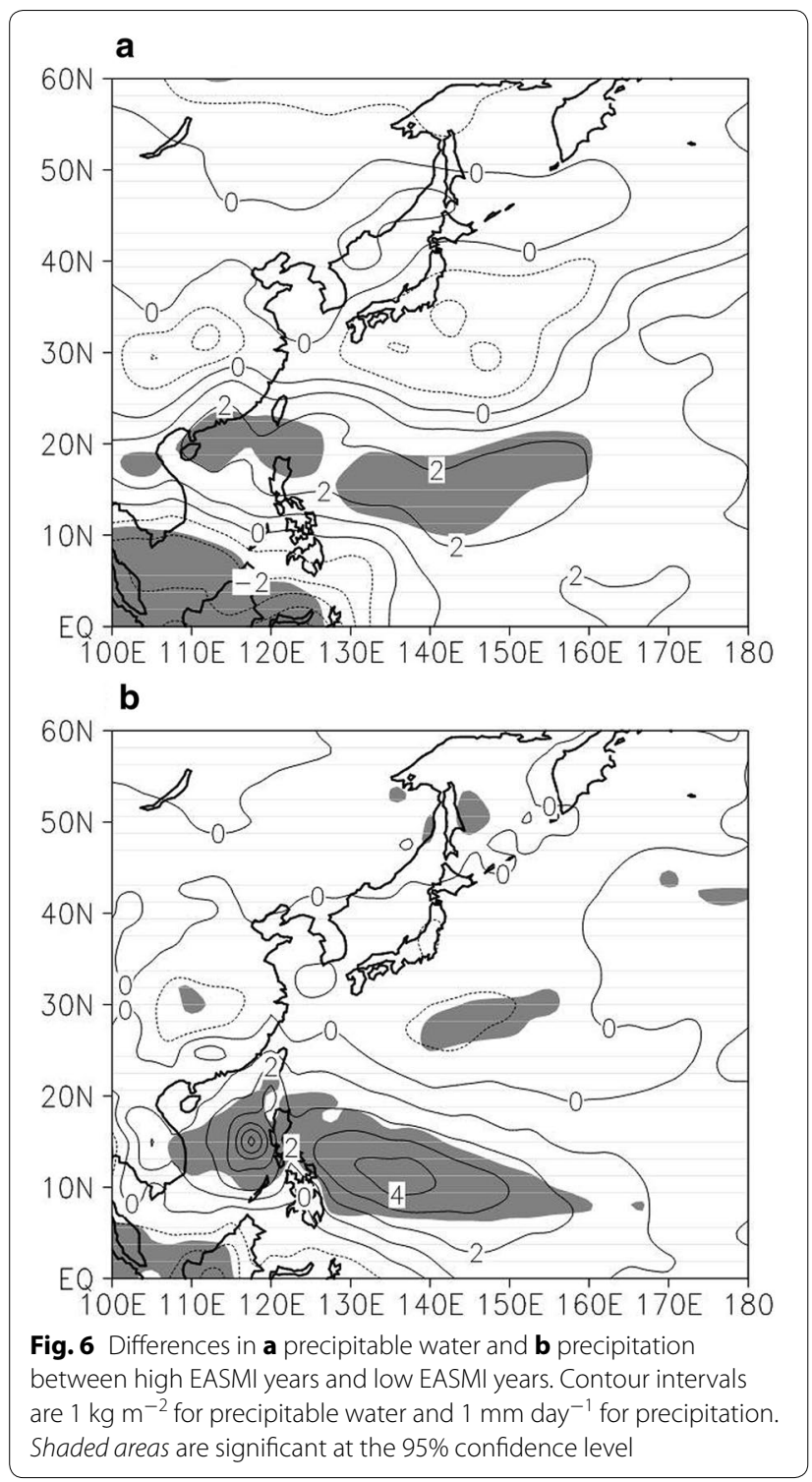

those shown by the results of analysis of differences in $500 \mathrm{hPa}$ streamlines (Fig. 7b). While anomalous cyclonic circulations were reinforced in the western North Pacific south to $30^{\circ} \mathrm{N}$, anomalous anticyclonic circulations were reinforced in mid-latitudes in the analysis area. In particular, because of the reinforcement of anomalous cyclonic circulations in the western North Pacific, more TCs could occur in high EASMI years as stated earlier.

Meanwhile, the reinforcement of anomalous cyclonic circulations in the western North Pacific in high EASMI years can be associated with reinforcement of monsoon troughs. Therefore, $850 \mathrm{hPa}$ streamlines in the two groups were analyzed (Fig. 8). While a monsoon trough developed eastward to $150^{\circ} \mathrm{E}$ in high EASMI years, almost no monsoon trough developed in low EASMI years. TC

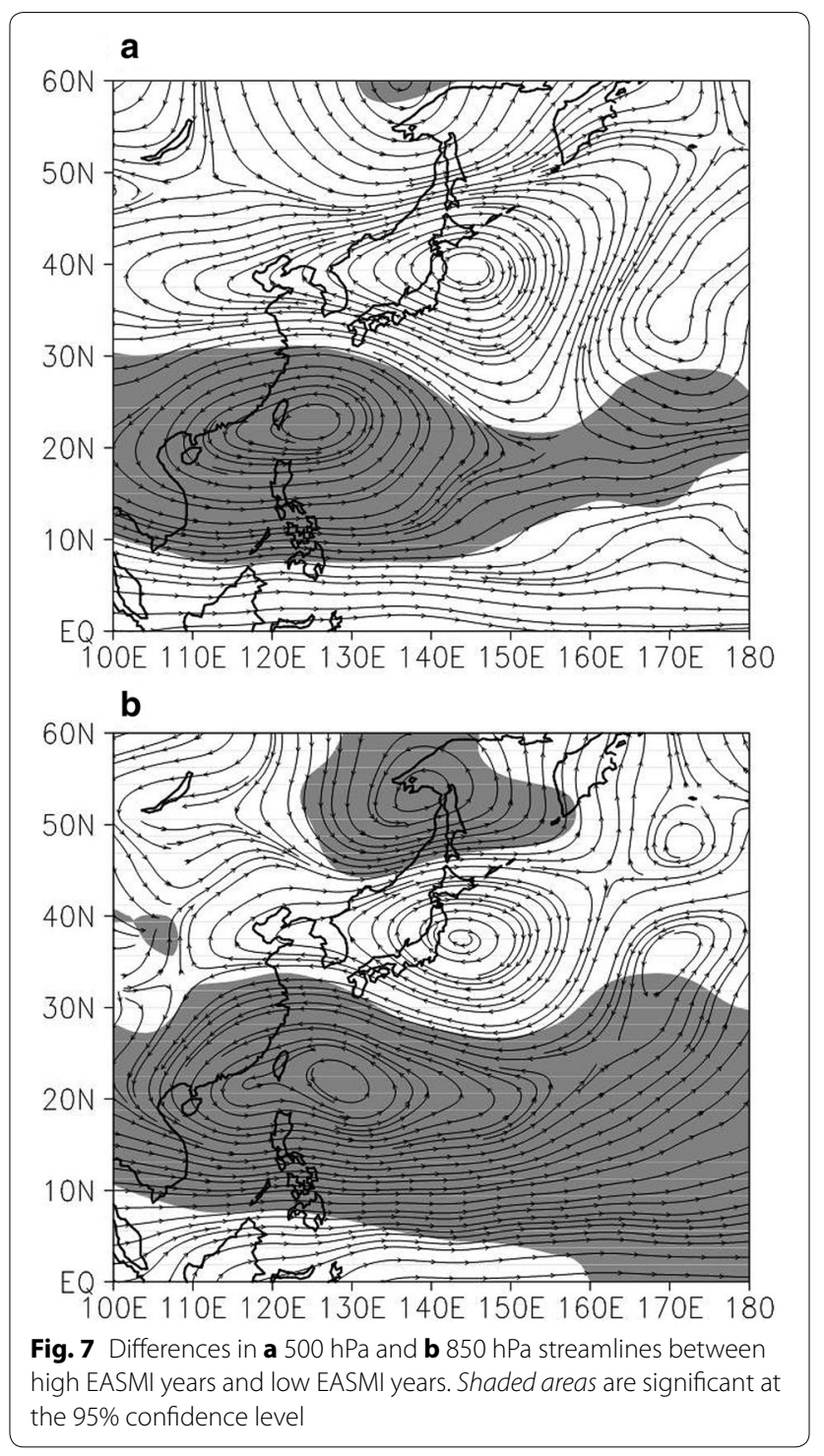

genesis frequency and TC genesis locations are generally associated with the degree and location of development of monsoon troughs (Gray 1975). Therefore, more TCs occur in high EASMI years when the monsoon trough is expanded further eastward and occur mainly in the east waters of the western North Pacific.

The degree of development of monsoon troughs in the two groups is associated with the degree of development of WNPSHs. Therefore, the degrees of development of WNPSHs in the two groups were analyzed (Fig. 4b). Here, WNPSHs are defined as areas having values larger than $5875 \mathrm{gpm}$ at $500 \mathrm{hPa}$. The WNPSH in low EASMI years when the monsoon trough was weak expanded westward to the southeastern coast of China. On the other hand, the WNPSH in high EASMI years when the monsoon trough was strong were weakened eastward. In 


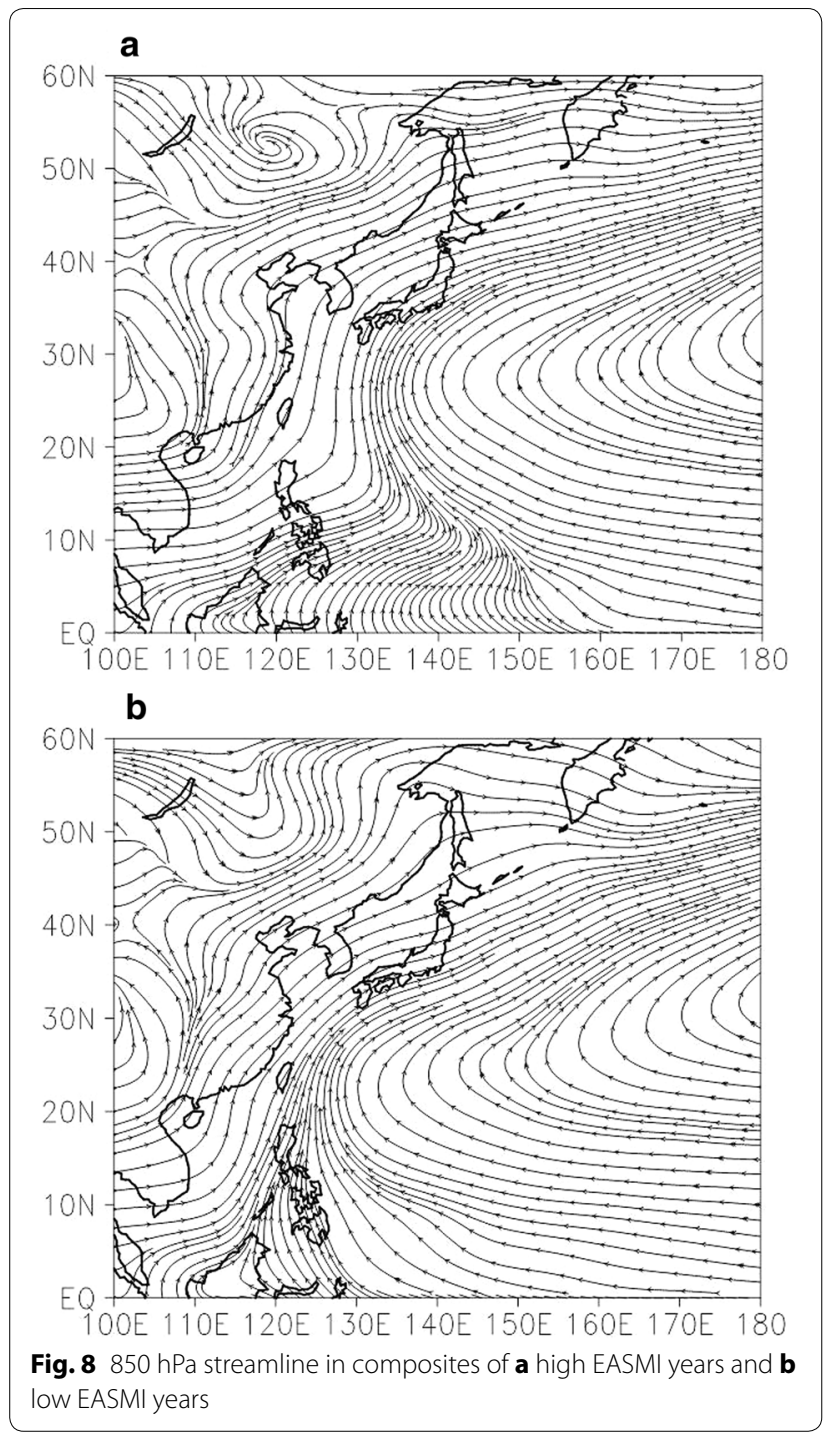

general, TCs tend to move along the western periphery of WNPSHs (Wang and Chan 2002). Therefore, the TC track of each group was almost identical to the western periphery of WNPSH, and TCs moved a little further to regions around Korea in high EASMI years when the WNPSH shrunk eastward.

Meanwhile, in high EASMI years, reinforcement of anomalous cyclonic circulations at the lower layer of the troposphere in the western North Pacific and reinforcement of anomalous anticyclonic circulations in the mid-latitudes can be identified through differences in horizontal divergence at the lower and upper layers of the troposphere between the two groups (Fig. 9). First, in the case of $850 \mathrm{hPa}$ horizontal divergence, while negative anomalies were reinforced in the western North Pacific, positive anomalies were reinforced in the mid-latitudes
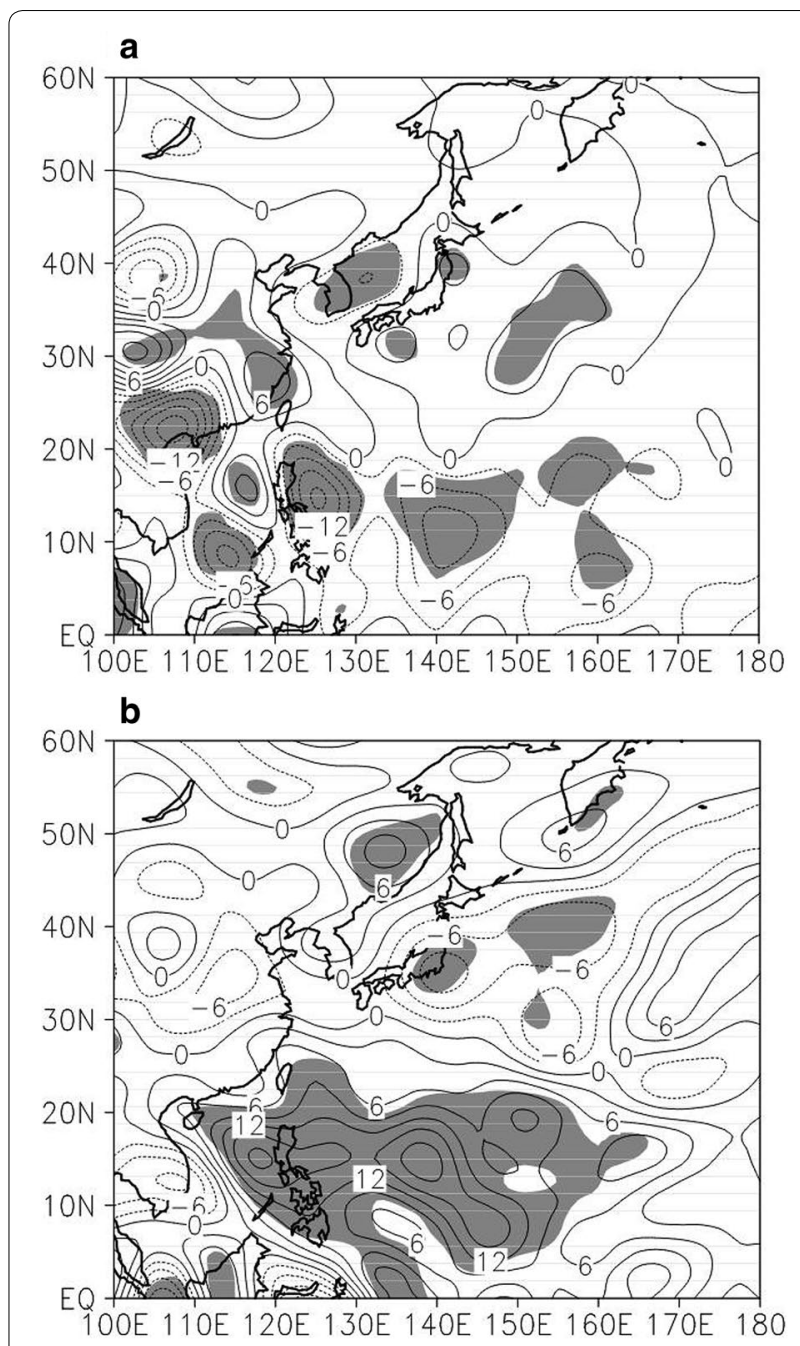

Fig. 9 Same as in Fig. 7, but for a $850 \mathrm{hPa}$ and $\mathbf{b} 200 \mathrm{hPa}$ horizontal divergences. Contour interval is $3 \mathrm{~s}^{-1} \times 10^{7}$. Shaded areas are significant at the $95 \%$ confidence level

of East Asia (Fig. 9a). This means that in high EASMI years, at the lower layer of the troposphere, while the horizontal convergence was reinforced in the western North Pacific, the horizontal divergence was reinforced in the mid-latitudes of East Asia. The spatial distribution of $200 \mathrm{hPa}$ horizontal divergence was opposite to that of $850 \mathrm{hPa}$ horizontal divergence (Fig. 9b). While the horizontal divergence was reinforced in the western North Pacific, the horizontal convergence was reinforced in the mid-latitudes of East Asia. Eventually, it can be seen that in high EASMI years, anomalous upward flows were formed in the western North Pacific, while anomalous downward flows were formed in the mid-latitudes of East Asia.

On the other hand, Fig. 4a shows that TC formation increases in the $130^{\circ}-150^{\circ} \mathrm{E}, 5^{\circ}-20^{\circ} \mathrm{N}$ region during the 
high EASMI years. They move with a recurving track along the western boundary of an eastward retreated Pacific subtropical high toward Korea. In the low EASMI years, TC formation tends to increase in the oceans to the east/southeast of Taiwan and affected by a westward expanded WNPSH to move westward toward the South China Sea. These analyses reveal two important features: variability of TC formation location and moving tracks. The composite $850 \mathrm{hPa}$ streamline in Fig. 8 explains the different steering effects of the WNPSH on the result in two different TC tracks between the high and low EASMI years. Also, composite anomalies of horizontal divergence (Fig. 9), relative humidity, and vertical wind shear (Fig. 12) explain the variability of TC formation.

To examine whether in high EASMI years, anomalous upward flows were actually formed in the western North Pacific, and anomalous downward flows were actually formed in the mid-latitudes of East Asia; differences in vertical meridional atmospheric circulations averaged in $100^{\circ}-180^{\circ} \mathrm{E}$ which is the longitudinal band where TCs mainly occur between the two groups were examined (Fig. 10a). Anomalous upwards flows were reinforced in the latitude band of $0^{\circ}-25^{\circ} \mathrm{N}$, while anomalous downward flows were reinforced in $25^{\circ}-40^{\circ} \mathrm{N}$. That is, this means that anomalous secondary circulations were formed in which air currents that ascended in the western North Pacific descended in the mid-latitudes of East Asia. Because of these vertical meridional atmospheric circulations, positive anomalies were formed in the latitude band of $0^{\circ}-30^{\circ} \mathrm{N}$, while negative anomalies were formed in $30^{\circ}-45^{\circ} \mathrm{N}$ in the analysis of relative humidity (Fig. 10b). This means that anomalous anticyclones were reinforced in the mid-latitudes of East Asia, and anomalous cyclones were reinforced in the western North Pacific. Therefore, in high EASMI years, not only TC genesis frequency but also the frequency of TCs that move northward to regions around Korea becomes high.

With regard to differences in 850 and $200 \mathrm{hPa}$ air temperatures between the two groups, warm anomalies were shown in the western North Pacific (excluding some waters) and the mid-latitudes of East Asia in high EASMI years (Fig. 11). These environments facilitate the occurrence of TCs in high EASMI years and enable TCs to maintain high TC intensity even when they have moved northward to regions around Korea.

With regard to differences in $600 \mathrm{hPa}$ relative humidity between the two groups, positive anomalies were shown in the western North Pacific south to $25^{\circ} \mathrm{N}$ and negative anomalies were shown in the mid-latitudes of East Asia in high EASMI years (Fig. 12a). Therefore, favorable environments for the occurrence of more TCs are formed in high EASMI years. In particular, since the center of positive anomalies is located in the east of the western North
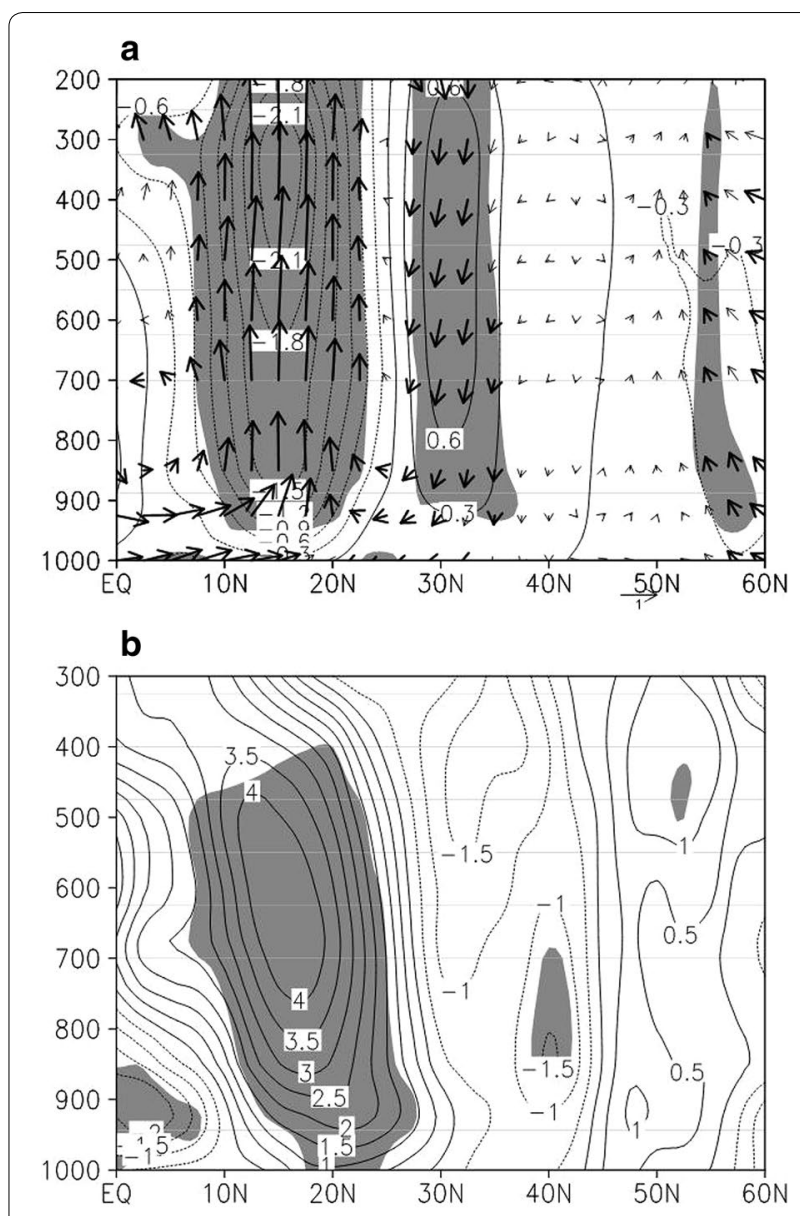

Fig. 10 Composite differences of latitude-pressure cross section of a vertical velocity (contours) and meridional circulations (vectors) and b relative humidity averaged along $100^{\circ}-180^{\circ} \mathrm{E}$ between high and Iow EASMI years for JJA. The values of vertical velocity are multiplied by -100 . Bold arrows and shaded areas are significant at the $95 \%$ confidence level. Contour intervals are $0.2^{-2} \mathrm{hPa} \mathrm{s}^{-1}$ for vertical velocity and $1 \%$ for relative humidity, respectively

Pacific, more TCs can occur in this region in high EASMI years.

With regard to differences in 200-850 hPa vertical wind shear between the two groups, negative anomalies were shown in all waters except for west waters of the western North Pacific and in the mid-latitudes of East Asia in high EASMI years (Fig. 12b). When the value of $200-850 \mathrm{hPa}$ vertical wind shear is smaller, differences in wind directions between the upper and lower layers of the troposphere are smaller so that TCs can occur easily, and high TC intensity can be maintained. Therefore, in high EASMI years, more TCs can occur in the western North Pacific, and high TC intensity can be maintained even when TCs have moved northward to regions around Korea.

To examine the characteristics of global-scale atmospheric circulations, differences in 850 and $200 \mathrm{hPa}$ 


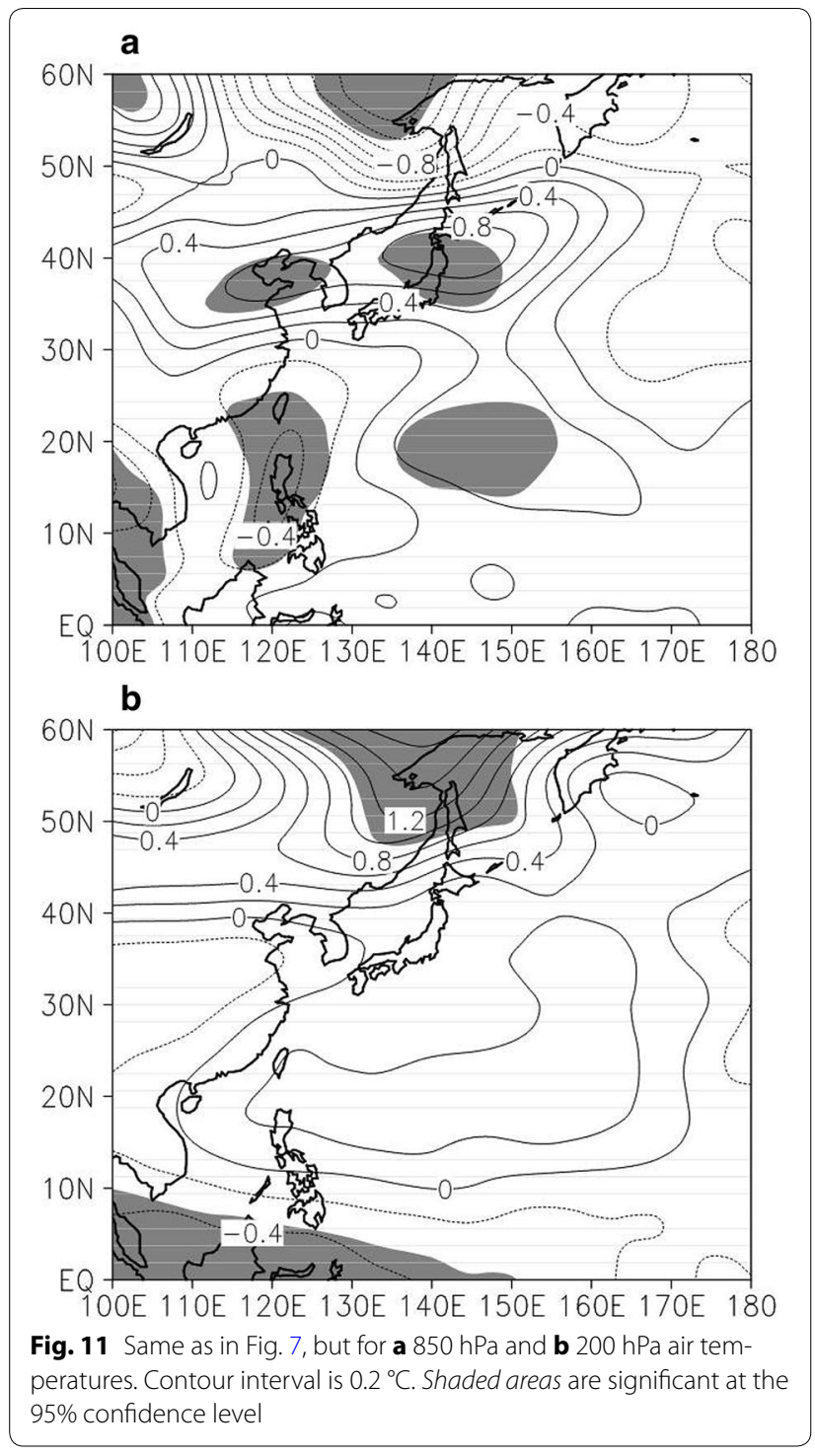

velocity potentials between the two groups were analyzed (Fig. 13). First, with regard to $850 \mathrm{hPa}$ velocity potential, positive anomalies were located in the Pacific and negative anomalies in regions west to the Pacific in high EASMI years (Fig. 13a). In the case of $200 \mathrm{hPa}$ velocity potential, spatial distributions opposite to those for $850 \mathrm{hPa}$ velocity potential were shown (Fig. 13b). Negative anomalies were reinforced in the Pacific, and positive anomalies were reinforced in regions west to the Pacific. In particular, the centers of negative anomalies and positive anomalies were located in the western North Pacific and the equatorial Indian Ocean, respectively. From these results, it can be seen that, in high EASMI years, the characteristics of global-scale atmospheric circulations were shown in which the air converged at the lower layer of the western Pacific was diverged at the upper layer,
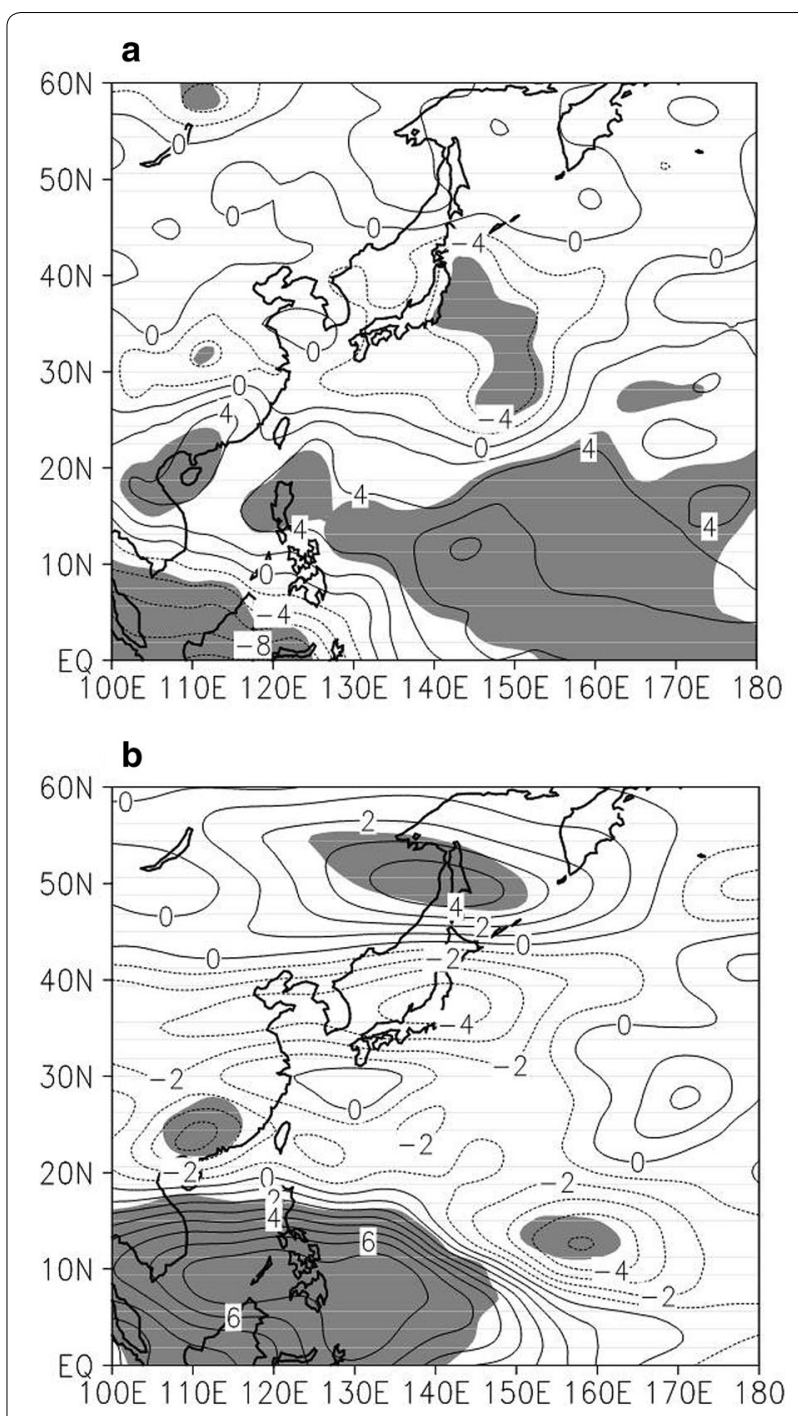

Fig. 12 Same as in Fig. 7, but for a $600 \mathrm{hPa}$ relative humidity and b vertical wind shear between 200 and $850 \mathrm{hPa}$. Contour intervals are $2 \%$ for $600 \mathrm{hPa}$ relative humidity and $1 \mathrm{~m} \mathrm{~s}^{-1}$ for vertical wind shear between 200 and $850 \mathrm{hPa}$. Shaded areas are significant at the 95\%

confidence level

moved to the west to converge at the upper layer of the equatorial Indian Ocean, and diverged at the lower layer.

The SST is also a variable that plays important roles for TC genesis and TC intensity. Therefore, differences in SST between the two groups were analyzed (Fig. 14). Since warm anomalies were shown in the southeastern sea of the western North Pacific, more TCs could occur in these waters in high EASMI years. In addition, warm anomalies were distributed in the mid-latitude waters of East Asia too so that important environments were formed that enabled TCs to maintain high intensity even when they have moved northward to regions around Korea in high EASMI years. The local SST near Korea is 


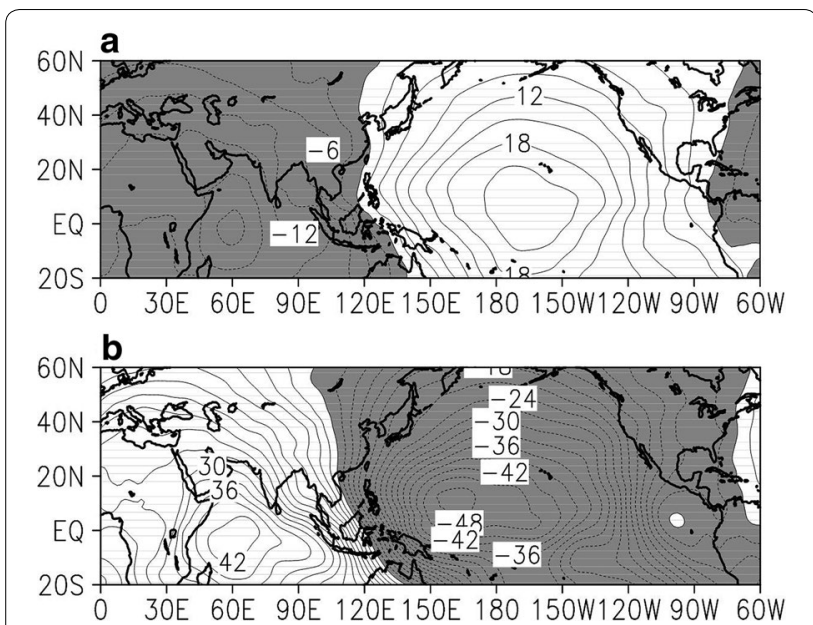

Fig. 13 Same as in Fig. 7, but for a $850 \mathrm{hPa}$ velocity potential and $\mathbf{b}$ $200 \mathrm{hPa}$ velocity potential. Shaded areas denote negative anomalies. Contour interval is $3 \mathrm{~m}^{2} \mathrm{~s}^{-1} \times 10^{-6}$

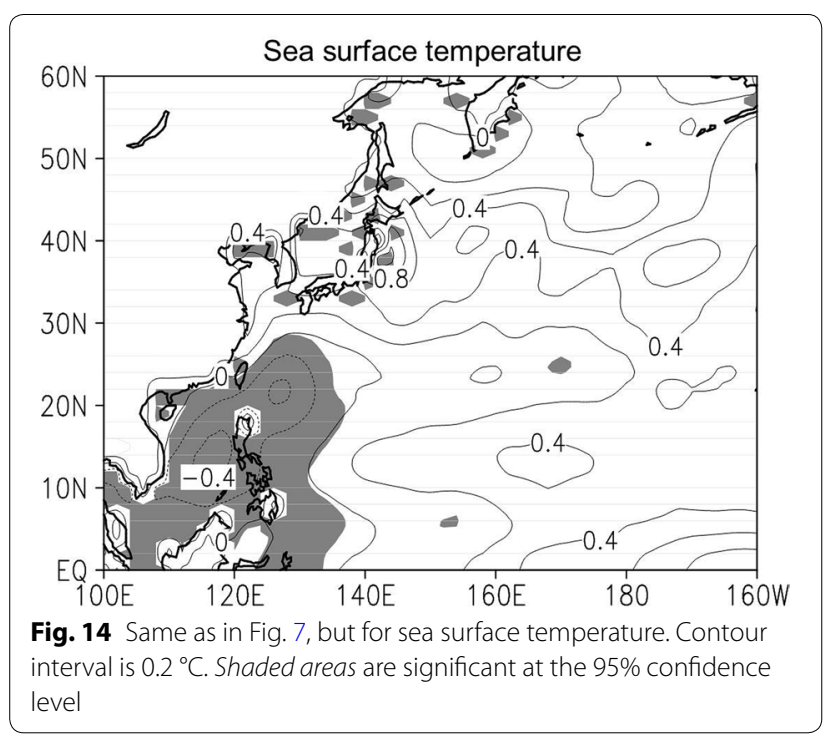

also warmer in high EASMI years, which can affect the TC intensification around Korea.

\section{Summary and conclusion}

In the present study, the correlations between the frequency of TCs that affected Korea in summer over the last 37 years and the EASMI defined by Li and Zeng (2002, 2003, 2005) were analyzed. Clear positive correlations existed between the two variables and the high positive correlations did not change even when ENSO years had been excluded. To examine the cause of these positive correlations between the two variables, 8 years having the highest EASMI (high EASMI years) and 8 years having the lowest EASMI (low EASMI years) except for
ENSO years were selected, and differences in averages between the two groups were analyzed.

In high EASMI years, TCs mainly occurred in the east waters of the western North Pacific and showed a tendency to pass the East China Sea and move northward toward regions around Korea. In low EASMI years, TCs mainly occurred in the west sea of the western North Pacific and showed a pattern of passing the South China Sea and moving westward toward the Indochina Peninsula. Therefore, TC intensity was higher in high EASMI years when TCs could obtain sufficient energy while moving long distances to regions around Korea. In addition, TCs showed a characteristic of occurring more frequently in high EASMI years than in low EASMI years.

With regard to differences in 850 and $500 \mathrm{hPa}$ streamlines between the two groups, anomalous cyclones were reinforced in the western North Pacific and anomalous anticyclones were reinforced in the mid-latitudes of East Asia in high EASMI years. Due to these two anomalous pressure systems, anomalous southeasterlies developed around Korea, and these anomalous southeasterlies played the role of anomalous steering flows to have TCs move toward regions around Korea. In addition, more TCs could occur in high EASMI years because of the anomalous cyclones developed in the western North Pacific.

The anomalous cyclones developed in the western North Pacific in high EASMI years were associated with the development of monsoon troughs. While the monsoon trough developed eastward to $150^{\circ} \mathrm{E}$ in high EASMI years, they hardly developed in low EASMI years. Therefore, some more TCs could occur in high EASMI years mainly in the east waters of the western North Pacific.

Differences in the degree of development of monsoon troughs between the two groups were associated with the degree of development of WNPSHs. While the WNPSH shrunk eastward in high EASMI years, it expanded to the southeastern coast of China in low EASMI years. Therefore, while TCs could move northward to regions around Korea in high EASMI years, they became to move westward toward the Indochina Peninsula in low EASMI years.

Meanwhile, anomalous anticyclones and anomalous cyclones developed in the mid-latitudes of East Asia and the western North Pacific, respectively, at the lower layer of the troposphere in high EASMI years could be identified through differences in horizontal divergences between the two groups. At the lower layer of the troposphere, anomalous convergences were reinforced in the western North Pacific and anomalous divergences were reinforced in the mid-latitudes of East Asia. At the upper layer of the troposphere, the opposite pattern was 
reinforced so that anomalous upward flows were formed in the western North Pacific, while anomalous downward flows were formed in the mid-latitudes of East Asia.

To examine whether these anomalous vertical atmospheric circulations were reinforced in high EASMI years, those circulations in $100^{\circ}-180^{\circ} \mathrm{E}$ where TCs mainly occur were averaged to analyze differences in vertical meridional atmospheric circulations between the two groups. Anomalous secondary circulations were formed in which air currents ascended in regions south to $25^{\circ} \mathrm{N}$ and descended in $25^{\circ}-40^{\circ} \mathrm{N}$. Because of the anomalous vertical meridional atmospheric circulations reinforced as such in high EASMI years, positive relative humidity anomalies were reinforced at all layers of the troposphere in regions south to $30^{\circ} \mathrm{N}$, while negative relative humidity anomalies were reinforced at all layers of the troposphere in $30^{\circ}-45^{\circ} \mathrm{N}$. These conditions of anomalous vertical meridional atmospheric circulations and relative humidity became favorable environments for more TCs to occur in high EASMI years and have more effects on regions around Korea.

Both the upper and lower layers of the troposphere showed warm anomalies in most regions in the analysis area. In the middle layer relative humidity of the troposphere, positive anomalies were shown in the western North Pacific to provide favorable environments for TC intensity to be reinforced further in high EASMI years. In addition, in $200-850 \mathrm{hPa}$ vertical wind shear, not only the western North Pacific but also the mid-latitudes of East Asia showed negative anomalies and mid-latitude waters of East Asia showed warm SST anomalies so that favorable environments were formed for TC intensity to be reinforced further in high EASMI years.

According to analyses of global-scale atmospheric circulations, in high EASMI years, the converged at the lower layer of the western North Pacific was diverged at the upper layer and the diverged air moved westward to converge at the upper layer of the equatorial Indian Ocean and diverge at the lower layer.

In the present study, the effects of EASM on TC activity around Korea were analyzed. These results are considered helpful for TC seasonal prediction for regions around Korea. In future studies, statistical TC seasonal prediction models will be developed using EASM.

\footnotetext{
Authors' contributions

JWC designed and carried out the study, and wrote the paper. YC provided detailed information on East Asian meteorological data. JYK acquired and processed the data of YC. JWC, YC, and JYK contributed extensively to the scientific discussion. All authors read and approved the final manuscript.
}

\section{Competing interests}

The authors declare that they have no competing interests.

\section{Funding}

This work was supported by the R\&D Project of the Korea Meteorological Administration "Development and application of technology for weather forecast."

Received: 2 September 2016 Accepted: 6 January 2017

Published online: 21 January 2017

\section{References}

Choi KS, Byun HR (2010) Possible relationship between western North Pacific tropical cyclone activity and Arctic Oscillation. Theor Appl Climatol 100:261-274

Choi KS, Kim BJ (2007) Climatological characteristics of tropical cyclones making landfall over the Korean Peninsula. Asia Pacific J Atmos Sci 43:97-109

Choi KS, Kim TR (2011) Regime shift of the early 1980s in the characteristics of the tropical cyclone affecting Korea. J Korean Earth Sci Soc 32:453-460

Choi KS, Kim DW, Byun HR (2009) Statistical model for seasonal prediction of tropical cyclone frequency around Korea. Asia Pacific J Atmos Sci 45:21-32

Choi KS, Kim BJ, Kim DW, Byun HR (2010) Interdecadal variation of tropical cyclone making landfall over the Korean Peninsula. Int J Climatol 30:1472-1483

Chu PS (2004) ENSO and tropical cyclone activity. In: Murnane RJ, Liu K-B (eds) Hurricanes and typhoons: past, present, and potential. Columbia University Press, New York, pp 297-332

Gray WM (1975) Tropical cyclone genesis. Dept. of Atmospheric Science Paper 234, Colorado State University, Fort Collins

Ho CH, Baik JJ, Kim JH, Gong DY, Sui CH (2004) Interdecadal changes in summertime typhoon tracks. J Clim 17:1767-1776

Ho CH, Kim JH, Kim HS, Sui CH, Gong DY (2005) Possible influence of the Antarctic Oscillation on tropical cyclone activity in the western North Pacific. J Geophys Res 110:D19104. doi:10.1029/2005JD005766

Kalnay E, Kanamitsu M, Kistler R et al (1996) The NCEP/NCAR 40-year reanalysis project. Bull Am Meteorol Soc 77:437-471

Kim JW, Lee JG (2007) A qualitative analysis of WRF simulation results of typhoon 'Rusa' Case. Atmosphere 17:393-405

Kim JH, Ho CH, Sui CH (2005) Circulation features associated with the recordbreaking typhoon landfall on Japan in 2004. Geophy Res Lett 32:L14713. doi:10.1029/2005GL022494

Kim YH, Jeon EH, Chang DE, Lee HS, Park JI (2010) The impact of T-PARK 2008 dropsonde observations on typhoon track forecasting. Asia Pacific J Atmos Sci 46:287-303

Kistler R, Kalnay E, Collins W et al (2001) The NCEP-NCAR 50-year reanalysis: monthly means CD-ROM and documentation. Bull Am Meteor Soc 82:247-267

Larson J, Zhou Y, Higgins RW (2005) Characteristics of landfalling tropical cyclones in the United States and Mexico: climatology and interannual variability. J Clim 18:1247-1262

Li JP, Zeng QC (2002) A unified monsoon index. Geophy Res Lett 29:1274. doi:1 $0.1029 / 2001 \mathrm{GL} 013874$

Li JP, Zeng QC (2003) A new monsoon index and the geographical distribution of the global monsoons. Adv Atmos Sci 20:299-302

Li JP, Zeng QC (2005) A new monsoon index, its interannual variability and relation with monsoon precipitation. Clim Environ Res 10:351-365

Lyon B, Camargo SJ (2009) The seasonally-varying influence of ENSO on rainfal and tropical cyclone activity in the Philippines. Clim Dyn 32:125-141

Nitta T (1986) Long-term variations of cloud amount in the western Pacific region. J Meteor Soc Jpn 64:373-390

Nitta T (1987) Convective activities in the tropical western Pacific and their impact on the Northern Hemisphere summer circulation. J Meteor Soc Japan 65:373-390

Nitta T (1989) Global features of the Pacific-Japan oscillation. Meteor Atmos Phys 41:5-12

Pan CJ, Reddy KK, Lai HC, Yang SS (2010) Role of mixed precipitating cloud systems on the typhoon rainfall. Ann Geophys 28:11-16

Park JI, Kim HM (2010) Typhoon Wukong (200610) Prediction based on the ensemble Kalman filter and ensemble sensitivity analysis. Atmosphere 20:287-306 
Park SK, Lee EH (2007) Synoptic features of orographically enhanced heavy rainfall on the east coast of Korea associated with Typhoon Rusa (2002). Geophys Res Lett 34:L02803. doi:10.1029/2006GL028592

Park JK, Km BS, Jung WS, Kim EB, Lee DG (2006) Change in statistical characteristics of typhoon affecting the Korean Peninsula. Atmosphere 16:1-17

Ramage CS (1971) Monsoon meteorology. Academic Press, New York

Reynolds RW, Rayner NA, Smith TM, Stokes DC, Wang W (2002) An improved in situ and satellite SST analysis for climate. J Clim 15:1609-1625

Wang B, Chan JCL (2002) How strong ENSO events affect tropical storm activity over the western North Pacific. J Clim 15:1643-1658

Wang B, Fan Z (1999) Choice of South Asian summer monsoon indices. Bull Am Meteor Soc 80:629-638

Wang HJ, Fan K (2007) Relationship between the Antarctic Oscillation in the western North Pacific typhoon frequency. Chin Sci Bull 52:561-565

Wang HJ, Sun JQ, Ke F (2007) Relationships between the north Pacific oscillation and the typhoon/hurricane frequencies. Sci China, Ser D Earth Sci 50:1409-1416
Wilks DS (1995) Statistical methods in the Atmospheric Sciences. Academic Press, New York

Wingo MT, Cecil DJ (2010) Effects of vertical wind shear on tropical cyclone precipitation. Mon Wea Rev 138:645-662

Wu MC, Chang WL, Leung WM (2004) Impacts of El Niño-Southern Oscillation events on tropical cyclone landfalling activity in the western North Pacific. J Clim 15:1419-1428

Xie P, Arkin PA (1997) Global precipitation: A 17-year monthly analysis based on gauge observations, satellite estimates, and numerical model outputs. Bull Am Meteorol Soc 78:2539-2558

Xie L, Yan T, Pietrafesa $\amalg$ (2005) Climatology and interannual variability of North Atlantic hurricane tracks. J Clim 18:5370-5381

\section{Submit your manuscript to a SpringerOpen ${ }^{\circ}$ journal and benefit from:}

- Convenient online submission

- Rigorous peer review

- Immediate publication on acceptance

- Open access: articles freely available online

- High visibility within the field

- Retaining the copyright to your article 